\title{
SISTEMA DE PROTECCIÓN FRENTE A LOS RIESGOS LABORALES EN EL DERECHO CHILENO
}

\section{SYSTEM OF PROTECTION AGAINST OCCUPATIONAL RISKS IN CHILEAN LAW}

\author{
PATRICIA FUENZALIDA MARTÍNEZ* \\ Juez Titular del Segundo Juzgado de Letras del Trabajo de Santiago
}

\begin{abstract}
RESUMEN: El presente trabajo analiza el modo en que la legislación nacional, autoriza la actuación conjunta y complementaria de normas de distinto origen y naturaleza, provenientes tanto del derecho civil como del derecho del trabajo y la seguridad social, a fin de brindar una protección oportuna e integral a aquel trabajador afectado por un accidente del trabajo o enfermedad profesional, indagando acerca de los requisitos de aplicación y características de cada una de ellas.
\end{abstract}

PALABRAS CLAVES: riesgos laborales; responsabilidad; reparación

ABSTRACT: This paper analyzes how the national law, authorizes the complementary and joint action of different origin and nature legislation, from both the civil law and the labour and social security law, in order to provide a protection inmediate and comprehensive of all their needs, for workers affected by an accident at work or occupational disease, inquiring about the application requirements and character of each a them.

KEY WORDS: occupational risk; liability; reparation

\section{I.- INTRODUCCIÓN}

El objeto del presente trabajo será analizar los mecanismos que contempla la legislación chilena para atender de manera integral, oportuna y suficiente, a aquel trabajador que ha sufrido un accidente del trabajo o enfermedad profesional, a fin de proveerle aquellas prestaciones necesarias para regresar su vida a un estado lo más cercano posible a aquel anterior a la ocurrencia del accidente, tanto desde el punto de vista médico como pecuniario.

Para ello, debemos tener presente que una de las principales características de la normativa nacional, en materia de accidentes del trabajo y enfermedades profesionales, es que permite la actuación, conjunta y en paralelo, de dos sistemas distintos de protección, uno enmarcado en las normas de la seguridad social y el otro en las normas del derecho civil, cada uno con sus propios fines, requisitos y procedimientos, ambos tendientes a reparar de distinto modo los daños causados por el accidente o enfermedad. Actuación conjunta que permite al trabajador beneficiarse de la celeridad del sistema de seguridad social y de la reparación integral que ofrece el sistema de responsabilidad civil.

De este modo, el trabajador que ha sufrido un accidente del trabajo o enfermedad profesional puede acceder a las prestaciones contempladas en el seguro obligatorio de accidentes del trabajo y enfermedades profesionales, seguro que forma parte del sistema de seguridad social y que opera de manera inmediata una vez ocurrido el accidente $o$ diagnosticada la enfermedad, otorgando prestaciones destinadas a recuperar la salud y

\footnotetext{
* Abogada; Licenciada en Ciencias Jurídicas de la Pontificia Universidad Católica de Chile; Magíster en Derecho del Trabajo por la Universidad Adolfo Ibáñez; Máster en Tutela de Derechos Fundamentales: La Protección Jurisdiccional en Materia de Género y Menores, por la Universidad de Jaén; Alumna Regular Programa Doctorado Universidad de Buenos Aires, entre otros; Juez Titular del Segundo Juzgado de Letras del Trabajo de Santiago; profesora de Derecho del Trabajo y de la Seguridad Social. Contacto: pfuenzalida@pjud.cl.
} 
mantener el ingreso, pero, además, en virtud del mismo accidente o enfermedad, el trabajador puede perseguir la responsabilidad civil de su empleador y, por esta vía, acceder al pago de indemnizaciones tendientes a reparar de manera integral los daños causados, en particular, aquellos que no hubieren sido cubiertos por el seguro, logrando de esta forma una reparación más completa y de mejor calidad.

La convivencia de ambos sistemas nos obliga a preguntarnos acerca de las características de uno y otro, cuáles son sus requisitos y elementos propios, en qué caso aplican, quién es el sujeto obligado, y cómo se deben compatibilizar las prestaciones otorgadas por cada uno, a fin de evitar que se produzca una doble reparación del mismo daño, que pudiere traducirse en un enriquecimiento ilícito o carente de causa de parte del trabajador, siendo dichas cuestiones las que contestaremos en las páginas siguientes, en las que analizaremos cada uno de dichos sistemas, para luego presentar algunas breves ideas respecto del modo en que ambos se relacionan y cómo lograr su adecuada coexistencia.

II.- NECESIDAD DE CONTAR CON UN SISTEMA DE PREVENCIÓN Y REPARACIÓN DE RIESGOS LABORALES

La doctrina y jurisprudencia suelen destacar como una de las principales características del Derecho del Trabajo, precisamente como aquella que lo distingue de las demás ramas del derecho privado, que este no se construye a partir del reconocimiento de la intrínseca igualdad de los contratantes, sino que se sitúa en la hipótesis contraria, estructurando sus normas desde el reconocimiento de la diferencia de poder existente entre los contratantes, asimetría que hace necesario brindar una especial protección a la parte débil.

Dicha protección se concreta en la existencia de normas de orden público, indisponibles para las partes, las cuales fijan cierto contenido mínimo del contrato en materias tales como remuneración, jornada u otras, pero, dado que quien se obliga a prestar servicios personales de manera subordinada, no sólo pone a disposición del empleador su tiempo y conocimientos, sino que toda su persona, incluida su propia corporalidad, dichas normas mínimas también contemplan una serie de obligaciones impuestas al empleador con la finalidad de proteger la vida y salud del trabajador, quien, en mérito de la necesidad que significa el tener que obtener los medios para sostener su vida y la de su familia, bien podría aceptar prestar servicios en condiciones riesgosas e inseguras.

En tal sentido, nuestro Código del Trabajo, contiene la norma base en materia de seguridad en su artículo 184, el cual prescribe: "El empleador estará obligado a tomar todas las medidas necesarias para proteger eficazmente la vida y salud de los trabajadores, informando de los posibles riesgos y manteniendo las condiciones adecuadas de higiene y seguridad en las faenas, como también los implementos necesarios para prevenir accidentes y enfermedades profesionales."

Sin embargo, la existencia de obligaciones en materia de prevención de riesgos no ha logrado evitar que estos se concreten, lo cierto, es que, sea por incumplimientos del empleador, del trabajador o la concurrencia de situaciones fortuitas, se siguen verificando tanto accidentes del trabajo como enfermedades profesionales. De manera que el afán protector de la norma debe proyectarse en dos sentidos, por una parte, debe arbitrar los medios para que en cada empresa o faena existan condiciones de trabajo seguras, acorde con la dignidad personal de los trabajadores que en ellas laboran, que eviten la ocurrencia de accidentes, y por otra parte, una vez que el riesgo se ha concretado, deben disponerse mecanismos idóneos que permitan al trabajador acceder a atención médica oportuna y suficiente para recuperar la salud, así como mantener un ingreso digno durante todo el período de recuperación. 
Históricamente, desde la revolución industrial y hasta la aparición y desarrollo del Derecho del Trabajo y del Derecho de la Seguridad Social, uno de los graves problemas que planteaba la ocurrencia de un accidente durante la faena, era que el trabajador no contase con los medios para atender a los gastos que le significaba el recuperar su salud, quedando en la más absoluta desprotección. A falta de normas laborales, la única respuesta que la legislación podría ofrecerle, estaba dada por las normas civiles, en particular, aquellas que establecían y regulaban la responsabilidad contractual, sin embargo, al fundarse tal régimen reparatorio en la culpa, el trabajador que quisiere hacer efectivas eventuales responsabilidades del empleador, debía enfrentar largos y costosos procesos, lo que significaba que esta no fuese una solución viable para solucionar aquellas necesidades que surgían de manera inmediata y con urgencia a consecuencia del accidente. Ante dicha realidad, las distintas legislaciones comienzan a buscar fórmulas basadas en la responsabilidad objetiva del empleador, que permitiesen garantizar al trabajador una prestación médica oportuna, traspasando sus costos al empleador, en tanto creador del riesgo, pero, aquello tampoco resultó ser una solución para todos los casos, ya que el trabajador cuyo empleador que carecía de bienes o lograba ocultar su patrimonio podía quedar en la misma situación de desprotección que antes de la aparición de tales normas. Es así que, finalmente, se desarrollan los seguros sociales obligatorios, destinados a proteger al trabajador frente a la ocurrencia de accidentes del trabajo y enfermedades profesionales, entregando su protección a un seguro financiado por trabajadores y empleadores, que permitía al trabajador acceder a prestaciones de manera inmediata una vez ocurrido el accidente y sin importar cuál fuese su situación económica o la de su empleador (Novoa, 1977: 328-335) (Humeres, 2005: 167-170).

En nuestro país, siguiendo una evolución similar y a la par con el desarrollo de la primera normativa laboral, se dictaron una serie de normas destinadas a prevenir y sancionar los accidentes del trabajo. Es así que el año 1916, se dicta la Ley $\mathrm{N}^{\circ} 3.170$ sobre accidentes del trabajo, que se erigía en la lógica de la responsabilidad patronal u objetiva, estableciendo la obligación del empleador de indemnizar al trabajador por los accidentes sufridos en las condiciones que la norma indicaba; norma reemplazada por las leyes 4.054 y 4.055 , dictadas el año 1926, que establecieron por primera vez un seguro social obligatorio frente a los riesgos de accidentes del trabajo y enfermedades profesionales, de financiamiento mixto, en el que, quien responde de las prestaciones correspondientes para el caso de accidente o enfermedad, ya no es el empleador, sino el organismo administrador; dichas normas fueron objeto de diversas modificaciones, hasta que, el año 1968, se promulga la ley 16.744, actualmente en vigencia, que establece normas sobre accidentes del trabajo y enfermedades profesionales, perfeccionado el sistema ya esbozado en la normativa anterior.

Pero, como adelantáramos, una característica especial de nuestro sistema, es que el desarrollo de esta normativa protectora, de carácter especial y que recoge los principios de la seguridad social, no significó dejar de lado las normas comunes sobre responsabilidad, previstas en la legislación civil, las que se siguieron aplicando, manteniéndose ambos plenamente vigentes y permitiéndose su acción complementaria (Domínguez, 2011: 21). De este modo, mediante la aplicación conjunta de ambas normas, se logra una protección de mejor calidad, que combina los requisitos de oportunidad y suficiencia que se exigen a toda prestación con pretensiones de eficacia. 


\section{III.- SISTEMA DE PROTECCIÓN SOCLAL PREVISTO POR LA SEGURIDAD SOCIAL PARA ATENDER A LOS RIESGOS LABORALES}

La Ley $\mathrm{N}^{\circ} 16.744$ de 1968, que establece normas sobre accidentes del trabajo y enfermedades profesionales, es la norma que regula actualmente la materia en nuestro país, disponiendo la creación de un seguro social contra riesgos de accidentes del trabajo y enfermedades profesionales, financiado por el empleador, por cuya aplicación quedan protegidos tanto los trabajadores dependientes del sector público y privado, como los trabajadores independientes y estudiantes, estos últimos, en relación con los accidentes que sufran a causa o con ocasión de sus estudios o de su práctica profesional, contemplando tanto normas relativas a la prevención de dichos accidentes y enfermedades, como prestaciones médicas y pecuniarias para el caso de verificarse un accidente o enfermedad profesional. Norma que se complementa con una serie de reglamentos, destinados a precisar distintos aspectos tanto en materia de prevención de riesgos laborales como de protección frente a la ocurrencia de un accidente del trabajo o enfermedad profesional.

De las características de la norma podemos concluir que ésta se construye en base a un sistema de responsabilidad que podríamos calificar como de responsabilidad social objetiva. Responsabilidad social, por cuanto las prestaciones son cubiertas, no por el empleador, sino por un seguro obligatorio, cuyo financiamiento se construye principalmente a través de cotizaciones del empleador, lo que supone que el pago de las prestaciones se independiza de la situación económica de la empresa, aportando mayor certeza de su otorgamiento; y objetiva, por cuanto, verificado el supuesto de hecho que establece la norma, cual es, la ocurrencia de un accidente ocurrido a causa o con ocasión del trabajo o diagnosticada una enfermedad causada de manera directa por el ejercicio de la profesión o el trabajo, el trabajador tiene derecho a las prestaciones médicas y pecuniarias que la misma prevé, con prescindencia de la existencia de culpa del propio trabajador o de su empleador, la que, de existir, podrá dar lugar a otras sanciones o responsabilidades, pero, que no incide en el otorgamiento de estas prestaciones.

De este modo, verificados los supuestos señalados, esto es, ocurrencia del accidente o diagnóstico de la enfermedad, el trabajador tendrá derechos a las prestaciones, con solo dos excepciones que permitirán a los organismos administradores rehusar su otorgamiento: accidentes debidos a fuerza mayor extraña, que no tenga relación alguna con el trabajo, y aquellos producidos intencionalmente por la víctima (Art. $5^{\circ}$ ). Lo anterior, significa que ocurrido el accidente se otorgarán las prestaciones respectivas, sin más requisitos que la propia existencia de un accidente susceptible de ser calificado como de origen laboral y que el trabajador concurra ante el organismo asegurador al cual se encuentra afiliado su empleador, sin que la conducta del empleador y trabajador sean relevantes para efectos del otorgamiento de las prestaciones, quedando cubiertos tanto los accidentes causados por la negligencia del trabajador o del empleador, por el actuar doloso del empleador o de un tercero, por caso fortuito, e incluso por fuerza mayor, si es que esta tiene algún vínculo o relación con la prestación de los servicios.

En efecto, al trabajador accidentado no se le requiere ningún tipo de prueba o declaración judicial previa para acceder a las prestaciones que contempla la ley, ocurrido que sea un accidente de aquellos que la ley califica como laboral, no necesita probar la existencia de un actuar culpable o doloso de parte de su empleador; tampoco necesita probar que él ha actuado de manera diligente, dado que la ley le garantiza el acceso a las prestaciones aun cuando haya actuado de manera negligente o culpable, y si el organismo administrador del seguro estima que el accidente se ha debido al dolo del trabajador, es dicho organismo quien 
debe acreditarlo; e incluso, si el accidente se ha debido a fuerza mayor, el trabajador no está obligado a explicar cómo la prestación de servicios lo puso en el lugar donde se verificó la fuerza mayor o cómo las labores aumentaron el riesgo al que estaba expuesto, siendo nuevamente el organismo administrador el que, de estimar que la fuerza mayor no tiene relación alguna con el trabajo, debe probar tal circunstancia. Lo anterior, por cierto, tiene importantísimos efectos en orden a garantizar que la prestación se reciba de manera oportuna, ya que el trabajador podrá concurrir a los servicios médicos respectivos desde el mismo momento en que se produzca el accidente y será también a partir de ese mismo momento que comenzará a percibir aquellos subsidios que reemplazarán a los ingresos que no producirá durante el período de recuperación, de manera que la ley le asegura el contar con un ingreso constante desde el momento de sufrir el accidente y hasta el alta, sin que deba para ello enfrentar ningún tipo de procedimiento judicial o administrativo.

Los únicos casos en que el trabajador podría tener que enfrentar un procedimiento judicial o administrativo previo, que lo habilite para acceder a las prestaciones de la ley, son aquellos en que se den una de las siguientes situaciones: cuando los organismos administrativos estiman que la lesión no es de origen laboral, sino común, caso en que de conformidad al artículo 77 bis de la Ley $\mathrm{N}^{\circ} 16.744$, las prestaciones médicas y pecuniarias serán otorgadas por el organismo administrador de las contingencias de salud común, pudiendo el trabajador concurrir ante la Superintendencia de Seguridad Social a fin que dirima el carácter de la afección ${ }^{1}$; una segunda hipótesis en que un trabajador podría tener que someterse a un procedimiento previo, en este caso de tipo judicial, es si su empleador no le reconoce la calidad de trabajador dependiente y, como consecuencia de ello, no lo ha incorporado al organismo administrador respectivo, caso en que el trabajador podría tener que accionar previamente a fin que se declarase su calidad de trabajador dependiente respecto de dicho empleador.

Es así que, constatado que el trabajador ha sufrido un accidente o enfermedad profesional y que ha concurrido al organismo administrador pertinente, tendrá derecho al otorgamiento de las prestaciones médicas y pecuniarias que consagra la ley, la cual, respecto de estas últimas, distingue dos etapas dentro de la evolución médica de la lesión: una primera etapa de carácter transitorio, la incapacidad temporal, durante la cual se otorgan los tratamientos destinados a recuperar la salud del trabajador; y una segunda, de carácter permanente, que se inicia al concluir el tratamiento, cuando se dispone sea el alta o la declaración de invalidez (Art. $27^{\circ}$ ). Distinción que será relevante para determinar la naturaleza de la prestación, que en el primer caso será un subsidio por incapacidad laboral y en el segundo caso, podrá ser una indemnización a suma alzada o una pensión de pago mensual.

Las prestaciones médicas consagradas por la ley, tienen por objeto la total recuperación del trabajador, no sólo a fin de restablecer su salud, sino de devolverlo a un estado lo más cercano a aquel que tenía en forma previa a la ocurrencia del accidente o a contraer la enfermedad, por lo que se consideran no sólo las propias atenciones médicas,

\footnotetext{
${ }^{1}$ En este caso, la norma en cuestión señala que la Superintendencia de Seguridad Social conocerá del reclamo "con competencia exclusiva y sin ulterior recurso", lo que ha llevado a numerosos Tribunales del Trabajo a declarar que no son competentes para conocer de reclamos interpuestos en contra de la decisión de la Superintendencia, por cuanto la propia ley excluiría la competencia judicial al señalar que la autoridad administrativa conoce de manera exclusiva, sin embargo, buena parte de esas decisiones han sido revocadas por las Cortes de Apelaciones respectivas invocando como argumento el principio de inexcusabilidad que prevé el artículo 76 inciso segundo de la Constitución Política de la República y lo previsto en el artículo 420 letra e) del Código del Trabajo. Como ejemplo de aquello podemos citar las causas: Castro con Superintendencia (2009); Correa con Superintendencia (2001); Carrasco con Superintendencia (2011); Damianovic con Superintendencia (2011); Herrera con Superintendencia (2011), entre otras.
} 
quirúrgicas y dentales, ambulatorias u hospitalarias, sino también los medicamentos y productos farmacéuticos, las prótesis y aparatos ortopédicos, así como su reparación, la rehabilitación física y reeducación profesional, los gastos de traslado, y cualquier otro que sea necesario para el otorgamiento de estas prestaciones (Art. $29^{\circ}$ ). Prestaciones que serán otorgadas durante el período de tratamiento y hasta el alta, proyectándose también hacia el futuro cuando el trabajador sea declarado inválido, caso en que, a lo menos, se prevé la realización de exámenes periódicos (Art. 64 $)$.

Ahora bien, dado que uno de los efectos de todo accidente o enfermedad profesional de gravedad media o alta, será impedir al trabajador el realizar de modo normal sus labores, la norma establece también el otorgamiento de prestaciones pecuniarias, tendientes a reemplazar el ingreso que deja de percibir, en forma transitoria, durante el período de tratamiento o, en forma permanente (desde la declaración de invalidez y hasta el cumplimiento de la edad legal que habilita a jubilar por vejez), como consecuencia de la declaración de incapacidad. Es a estos efectos que, como señaláramos previamente, la ley distingue entre incapacidad temporal, cual es, aquella situación en que se ve impedido de trabajar como consecuencia del accidente y que puede durar hasta 52 semanas, prorrogables por otras 52 semanas (Art. $31^{\circ}$ ); e invalidez, que se declarará cuando los médicos tratantes estimen que el trabajador ha sufrido una pérdida en su capacidad de ganancia, presumiblemente permanente, de a lo menos un $15 \%$, la que a su vez se subclasifica en invalidez parcial, total y gran invalidez (Arts. $27^{\circ}$ y siguientes). Todo ello, sin perjuicio de las prestaciones por sobrevivencia, previstas para el caso del fallecimiento del trabajador a causa del accidente o enfermedad profesional.

Durante el período en que el trabajador se ve impedido de trabajar por aquejarle una incapacidad temporal, tiene derecho al pago de un subsidio por incapacidad laboral, equivalente al promedio de su remuneración deducidas cotizaciones e impuestos, (Arts. $30^{\circ} \mathrm{y}$ siguientes de la Ley $\mathrm{N}^{\circ} 16.744$, en relación a los Arts. $7^{\circ}$ y $8^{\circ}$ del DFL 44 de 1978 del Ministerio del Trabajo y Seguridad Social, sobre subsidios por incapacidad laboral), el que percibirá durante todo el tiempo que dure la incapacidad, sin perjuicio de preverse la posibilidad de suspender su pago cuando el trabajador dificulte o impida su curación. En tanto que, para el caso de declararse una invalidez, dependiendo de su gravedad, el trabajador podrá percibir desde una indemnización global, de pago único, hasta pensiones por invalidez, de pago mensual, desde la declaración de la invalidez y hasta la fecha en que el trabajador cumpla la edad legal para pensionarse por vejez.

El pago de la indemnización prevista en esta ley, procede cuando el trabajador sufre una incapacidad parcial de primer grado, esto es, una pérdida de capacidad de ganancia superior al $15 \%$ e inferior al $40 \%$. Se trata de una indemnización cuyo monto no excederá de 15 veces el sueldo base del trabajador, cuyo monto se determinará en función de la relación entre dicho máximo y el valor asignado a la incapacidad respectiva, también percibirá esta indemnización aquel trabajador que, sin sufrir incapacidad, sufra un accidente que le produjere una mutilación importante o una deformación notoria, disponiéndose para casos de especial gravedad, como es aquella mutilación importante o deformación notoria que afecte a la cara, cabeza u órganos genitales, que el pago de la indemnización deba ser siempre en su monto máximo (Arts. $35^{\circ}$ a $37^{\circ}$ ).

En cuanto a las pensiones, estas se percibirán en los siguientes casos y por los siguientes montos: si la pérdida de capacidad es superior al $40 \%$ e inferior al $70 \%$, se configura una incapacidad parcial de segundo grado, que da derecho al trabajador a percibir una pensión de pago mensual, equivalente al 35\% de su sueldo base; si la incapacidad es total, esto es, superior al 70\%, la pensión mensual será equivalente al $70 \%$ de su sueldo base; por último, si se trata de un gran invalido, esto es, quien requiere del auxilio de otras personas para realizar los actos elementales de su vida, el trabajador percibirá la pensión 
correspondiente al invalido total, más un suplemento equivalente al 30\% de su sueldo base, lo que significa que mientras permanezca en tal estado, sumada la pensión base y el suplemento, percibirá una pensión equivalente al $100 \%$ de su sueldo base. Montos que se incrementarán, con los máximos que establece la ley, en un $5 \%$ por cada hijo que le cause asignación familiar, en exceso de dos (Arts. $34^{\circ}$ y siguientes). Todas estas prestaciones se pagarán al trabajador, previa determinación del Servicio de Salud o la Mutualidad respectiva, sobre la existencia de la incapacidad temporal o, en su caso, de la invalidez y del porcentaje preciso de pérdida de capacidad de ganancia.

Ahora bien, dado que la Ley $\mathrm{N}^{\circ} 16.744$ forma parte del sistema de seguridad social, para analizar y evaluar las prestaciones que otorga, debemos necesariamente hacerlo a la luz de los fines y principios de la seguridad social. Desde el punto de vista de los fines propios de la seguridad social (ver Novoa, 1977: 54), debemos preguntarnos si dichas prestaciones logran cuidar la salud de los trabajadores, mediante acciones médicas preventivas, curativas y de rehabilitación, y si logran otorgar prestaciones pecuniarias, substitutivas del salario, sueldo o renta de que disfrutaba la persona, en caso de suspensión, disminución o terminación de su capacidad de ganancia; en tanto que, desde el punto de vista de los principios ${ }^{2}$, nos preguntaremos si lo hacen de manera solidaria, universal, uniforme, e integra y suficiente.

Respecto de las prestaciones médicas, la ley contempla tanto acciones preventivas, como curativas y de rehabilitación, las que, según se ha descrito previamente, se otorgan de una manera bastante expedida, con el sólo requisito que el accidente o enfermedad sea declarado como de origen laboral o profesional, y consideran tanto las acciones médicas para lograr la propia curación de la enfermedad, como los medicamentos, traslados y, de ser necesario, prótesis, elementos ortopédicos, rehabilitación física y reeducación profesional, prestaciones que son otorgadas del mismo modo a todos los sujetos protegidos por la ley, sin perjuicio del organismo administrador en concreto al cual se encuentre afiliado el empleador. De manera que, en lo que dice relación con las prestaciones médicas, podemos concluir que estas resultan ser un medio idóneo para cumplir con los fines de la seguridad social, en cuanto a la protección de la salud en sus distintas etapas, y que, además, lo hacen de un modo acorde con los distintos principios de la dicha especialidad.

Por otra parte, en cuanto a las prestaciones pecuniarias, debemos distinguir entre las distintas prestaciones previstas en la ley, esto es, subsidios, indemnizaciones y pensiones. En cuanto a los subsidios, prestación económica prevista por la ley para el caso de la incapacidad temporal, esta parece suficiente y apropiada para el cumplimiento de su fin propio, cual es, reemplazar aquella remuneración que se deja de percibir durante el período de licencia médica, dado que el subsidio se calculará justamente en base a la remuneración que percibía el trabajador en actividad, deducidos los impuestos, cotizaciones y también aquellos estipendios no remuneracionales tales como horas extraordinarias, viáticos, y asignaciones de colación y movilización, lo que importará que el monto obtenido por el trabajador por este concepto, si bien normalmente será inferior al sueldo líquido que percibiría, tenderá a acercarse a aquel. De este modo, pese a tratarse de un monto que normalmente no alcanzará al sueldo líquido que percibía el trabajador en actividad, dado que al encontrarse en reposo el trabajador no incurrirá en aquellos gastos que lo habilitan para poder prestar sus servicios, tales como locomoción y otros, y que tampoco deberá incurrir en gastos a consecuencia del tratamiento médico, ya que dichos costos son todos de cargo del organismo administrador, podemos concluir que el monto del subsidio logra reemplazar de manera suficiente su ingreso

\footnotetext{
${ }^{2}$ Con ciertos matices en sus nombres o contenido, la doctrina mayoritaria reconoce como principios de la seguridad social, los siguientes: solidaridad, universalidad, en sus vertientes objetiva y subjetiva, unidad o uniformidad, integridad, y eficacia o suficiencia. (Novoa, 1977: 83), (Humeres, 2005: 32), (Cifuentes, Arellano, Walker, 2013: 53), (Lanata, 2015: 24).
} 
habitual y que aquello ocurre de un modo acorde a los principios que regulan la materia, sin perjuicio de reiterar que los subsidios tienen por finalidad reemplazar la remuneración que se deja de percibir a consecuencia del accidente y no reparar en forma íntegra todos los daños que de aquel se deriven al trabajador y su familia.

En materia de aquella indemnización que prevé la ley, para el caso del invalido parcial de primer grado, si bien su monto puede considerarse no tan elevado, ya que se otorga un máximo equivalente a 15 veces el sueldo base del trabajador, debemos considerar que la ley contempla dicha prestación respecto de trabajadores cuya incapacidad es menor a un $40 \%$, lo que significa que podrán seguir desempeñando labores y proveyéndose un ingreso, o incluso, como ocurre en casos de mutilaciones y deformidad, sin que se requiera de incapacidad alguna. Además, la indemnización se paga inmediatamente determinada que sea, por los organismos pertinentes, la existencia de cierta lesión o porcentaje de pérdida de capacidad, eximiendo al trabajador de la carga de rendir prueba alguna que acredite el daño efectivamente sufrido y su entidad, elementos que la ley presume a estos efectos, a partir del cumplimiento de las condiciones que se establecen en aquella y su reglamento, lo facilita enormemente el acceso del trabajador a esta prestación, cuestión que debe llevarnos a efectuar una evaluación positiva de aquella.

Finalmente, respecto de las pensiones por invalidez, si bien podemos reiterar que estas se otorgan de manera expedida y sin imponer demasiadas cargas o requisitos al trabajador, más que la declaración de determinado porcentaje de incapacidad, sus montos son bajos, permitiendo apenas solventar un nivel de vida mínimo o suficiente por parte del trabajador y sus familias, pero, difícilmente puede decirse que logren reemplazar de manera íntegra las remuneraciones que el trabajador percibía en actividad. Así, por ejemplo, un trabajador cuya pérdida de capacidad de ganancia sea superior al 50\%, difícilmente se sentirá en condiciones de continuar desempeñando los mismos servicios que realizaba antes del accidente y, si en atención a lo reducido de su capacidad remanente debe buscar otro empleo distinto, probablemente la invalidez que presenta le dificultará contratarse en condiciones similares a aquellas con que contaba en forma previa al accidente, y pese a todas estas dificultades, la ley le otorga una pensión que apenas se eleva por sobre un tercio de la remuneración que percibía al momento de accidentarse.

Luego, si la invalidez es total, es claro que la situación resulta ser mucho más grave, ya que, si para un trabajador con invalidez parcial es difícil seguir trabajando, es sencillo imaginarse las complicaciones que supondrá a un trabajador con más del $70 \%$ de pérdida de capacidad de ganancia el salir de su hogar a diario para realizar labores de manera continua durante varias horas. De manera que, suponiendo que la gravedad de su incapacidad le impida seguir trabajando, ese trabajador habrá visto desaparecer su sueldo, el que solo será reemplazado por una pensión equivalente al $70 \%$ de aquel, existiendo una pérdida en sus ingresos que deberá ser asumida por su familia.

Por último, en el caso del gran invalido, la situación se vuelve crítica, ya que no sólo es claro que dicho trabajador no podrá volver a trabajar, sino que, además, dado que la propia definición de gran invalidez supone que requiera auxilio de terceros para desarrollar los actos más elementales de la vida, una vez que el trabajador reciba el alta hospitalaria y pueda volver a su hogar, alguien en más en su familia deberá dejar de trabajar para auxiliarlo o la familia deberá asumir el costo de contratar a alguien que lo ayude con dichos actos elementales, tales como alimentarse y asearse. En definitiva, en el caso de este trabajador, la pérdida en términos de ingresos para su familia excederá de la remuneración completa del trabajador accidentado, ya que se pierde su sueldo y el de aquella persona que asuma su cuidado, o bien, se pierde su sueldo y se debe asumir el costo de un cuidador, y no obstante aquello, la pensión solo reemplazará un ingreso. 
Entonces, respecto de las pensiones que prevé la ley para el caso de invalidez parcial de segundo grado, invalidez total y gran invalidez, podemos señalar que estas no cumplen a cabalidad con el estándar de suficiencia que exigen los principios de la seguridad social, en particular, en cuanto a reemplazar aquella remuneración que el trabajador dejará de percibir, ya que si bien se trata de una prestación garantizada, que recibe toda persona que se encuentre en la hipótesis respectiva, su monto apenas permitirá alcanzar un estándar mínimo de sobrevivencia, que difícilmente permitirá, al trabajador y su familia, seguir llevando aquella vida digna que la seguridad social debiera garantizar a toda persona.

Es precisamente ante esta constatación de insuficiencia y atendido que las pensiones, subsidios e indemnización previstos en la ley, no pretenden lograr la reparación integral de los daños causados por el accidente, sino que solo apuntan a la mantención del ingreso del trabajador afectado, que resulta de suma importancia la norma contenida en el artículo 69 de la ley. Norma que permite al trabajador accidentado, perseguir, en adición y de manera complementaria a las prestaciones de la ley en comento, aquellas indemnizaciones que reparen los daños efectivamente causados por el accidente, de parte de quienes hayan concurrido a su materialización, sea en virtud de un actuar culpable o doloso. El artículo 69 de la Ley $\mathrm{N}^{\circ} 16.744$, dispone:

"Cuando, el accidente o enfermedad se deba a culpa o dolo de la entidad empleadora o de un tercero, sin perjuicio de las acciones criminales que procedan, deberán observarse las siguientes reglas:

a) El organismo administrador tendrá derecho a repetir en contra del responsable del accidente, por las prestaciones que haya otorgado o deba otorgar, $y$

b) La víctima y las demás personas a quienes el accidente o enfermedad cause daño podrán reclamar al empleador o terceros responsables del accidente, también las otras indemnizaciones a que tengan derecho, con arreglo a las prescripciones del derecho común, incluso el daño moral."

De este modo, el trabajador afectado, así como las demás personas a quienes se otorga legitimación activa para perseguir esta responsabilidad, puede requerir el pago de las indemnizaciones que procedan, inclusive el daño moral, en adición a las prestaciones contempladas en la Ley $\mathrm{N}^{\circ} 16.744$, siempre y cuando, como ordena la norma, acredite en el procedimiento respectivo que el accidente se ha debido a culpa o dolo de aquel a quien pretende hacer responsable del daño causado, sea el empleador o un tercero. Apareciendo, como pregunta a resolver, la determinación acerca de cuál es el procedimiento respectivo al que alude la norma, la que se limita a señalar que ello debe efectuarse "con arreglo a las prescripciones del derecho común".

A este respecto, es posible sostener que la referencia al derecho común que contiene la norma, importa que las reglas de fondo a aplicar no serán otras que las consagradas en el derecho civil, estatuto que consagra y regula los sistemas de responsabilidad contractual y extracontractual, de los cuales deriva la obligación de reparar los daños causados a terceros a consecuencia de un actuar culpable o doloso. Lo anterior, máxime que el Código del Trabajo no contempla expresamente ninguna norma que contenga obligación alguna en orden a indemnizar los perjuicios causados por los accidentes que sufran los trabajadores con ocasión de los servicios prestados, lo que hace necesario acudir al ordenamiento civil donde dicha obligación encuentra su fundamento.

En tanto que, en materia de procedimiento, debemos distinguir aquellos casos en que las partes, demandante y demandada, se encuentren unidas por un vínculo de naturaleza laboral y aquellos en que no, ya que en la primera hipótesis corresponderá aplicar el procedimiento laboral y en la segunda deberemos acudir a la normativa civil también en materia procedimental. Ello, por cuanto el artículo 420 letra f) del Código del Trabajo, señala 
que será de competencia de los Juzgados de Letras del Trabajo: "los juicios en que se pretenda hacer efectiva la responsabilidad del empleador derivada de accidentes del trabajo o enfermedades profesionales, con excepción de la responsabilidad extracontractual a la cual le será aplicable lo dispuesto en el artículo 69 de la ley $N .^{\circ} 16.744 ”$, norma de la cual se desprende que cuando el trabajador demande la responsabilidad civil de su empleador, con quien estaba unido por un vínculo contractual, deberá hacerlo de conformidad a las reglas previstas en el procedimiento ordinario laboral, en tanto que si quien quisiere hacer efectiva dicha responsabilidad del empleador sea un tercero, que no se encuentre unido a aquel por vínculo laboral, o si el trabajador accionare en contra de un tercero, con quien no haya celebrado contrato de trabajo, tales acciones, destinadas a hacer efectiva una responsabilidad de carácter extracontractual, deberán ser conocidas por los Tribunales Civiles respectivos, ya que en ninguno de estos supuestos resultaría aplicable el citado artículo 420 letra f), que se refiere a los juicios en que se pretenda hacer efectiva la responsabilidad del empleador, calificativo que solo resulta posible en el contexto de un contrato de trabajo, lo que importa que las partes necesariamente deben estar unidas por un vínculo de subordinación y dependencia, o haberlo estado a la época de los hechos, único supuesto que permite y justifica la actuación de un Tribunal Especial como son los Juzgados de Letras del Trabajo.

\section{IV.- LA RESPONS ABILIDAD CIVIL DEL EMPLEADOR POR ACCIDENTES DEL TRABAJO: NATURALEZA JURIDICA Y ELEMENTOS QUE LA CONFIGURAN}

El Código Civil nacional, siguiendo una tradición que encuentra su origen ya en el Derecho Romano y replicando la conceptualización de su par francés, establece no solo un sistema destinado a hacer efectiva la responsabilidad de las personas por los daños que puedan causar mediante sus acciones cuando estas no se realizan con la debida prudencia o corrección, sino que, además recoge la distinción entre la responsabilidad que emana del incumplimiento contractual y aquella derivada del hecho ilícito, regulando la primera en su "Título XII del Libro IV Del Efecto De Las Obligaciones", y la segunda en su "Título XXXV del Libro IV De Los Delitos Y Cuasidelitos".

En materia de daños derivados de accidentes del trabajo resultarán aplicables ambos sistemas de responsabilidad, pero, cada uno para distintos supuestos fácticos. Será aplicará el régimen de responsabilidad extracontractual cuando el accidente haya sido causado por un tercero, distinto del empleador, que no se encuentre unido por vínculo contractual con la víctima, o cuando quien reclama el daño no es el trabajador, sino terceros, tales como sus herederos u otros, quienes, aun cuando puedan tener el carácter de víctimas por repercusión, no se encuentran unidas por vínculo contractual con el empleador cuya responsabilidad se persigue. En tanto que resultará aplicable el régimen de responsabilidad contractual, cuando sea el propio trabajador quien reclame a su empleador los daños causados por el accidente, debiendo agregar a esta hipótesis, la posibilidad de que a ese mismo proceso sea traída, como demandada, la empresa mandante, con quien, por efectos de las normas sobre subcontratación, existe también un vínculo contractual, al menos indirecto, asignándole la ley a dicha empresa obligaciones de naturaleza laboral, que impiden que a su respecto hablemos de un tercero absoluto a quien le sea aplicable el régimen extracontractual, ello siempre y cuando se haga parte en el mismo proceso al empleador y sus mandantes, respetando la cadena de contratos y subcontratos celebrados entre el empleador y aquellos, ya que si el trabajador quisiere accionar únicamente contra ese mandante -y no contra su empleador-, al romper dicha cadena contractual y sustraerse de las normas sobre subcontratación, debieran 
aplicársele, respecto de ese tercero, las mismas reglas que a cualquier otro tercero ajeno a la relación laboral.

La distinción anterior es relevante, no sólo a fin de determinar las normas de fondo aplicables en uno y otro caso, sino también el procedimiento. Ello, por cuanto, como señaláramos previamente, cuando se trate de aquella acción ejercida por el trabajador en contra del empleador, de conformidad al artículo 420 f) del Código del Trabajo, resultará competente para conocer del asunto el Juez del Trabajo, quien aplicará los procedimientos y principios formativos del proceso previstos en dicho cuerpo legal; en tanto que, la excepción a su competencia, por así disponerlo la misma norma, son precisamente aquellos casos en que la responsabilidad reclamada sea de naturaleza extracontractual, caso en que será competente el Juez Civil, quien conocerá y fallará de acuerdo a los procedimientos y principios específicos de dicha sede jurisdiccional. En punto, parece conveniente precisar que la convivencia de ambos sistemas de responsabilidad no debiera suponer un derecho de opción al afectado, como se ha planteado desde ciertos sectores de la doctrina (Zelaya, 2005: 104), dado que, si concordamos en que las normas procesales son de orden público y, por tanto, indisponibles para las partes, salvo que aquellas expresamente establezcan un derecho a opción, lo cierto es que el actor no debiera poder elegir qué régimen de responsabilidad y, en consecuencia, qué procedimiento invocar, sino que debiera accionar en aquel que le corresponda según la naturaleza del vínculo que unía a las partes a la época de ocurrir el hecho dañoso, si existía contrato de trabajo, la responsabilidad deberá ser contractual y la sede laboral, en tanto que si las partes no estaban unidas por dicho vínculo, la responsabilidad que se reclame deberá ser extracontractual y el procedimiento a aplicar será el previsto para los asuntos civiles.

En materia de responsabilidad contractual, caso que analizaremos en las páginas siguientes, debemos estarnos a lo previsto en los artículos 1545 y siguientes del Código Civil. Ahora bien, como la responsabilidad derivada de daños producidos a consecuencia de accidentes del trabajo, se origina en el incumplimiento por parte del empleador de una obligación de hacer, esto es, en el incumplimiento o cumplimiento insuficiente del empleador del llamado "deber de seguridad" establecido en el artículo 184 del Código del Trabajo y su normativa legal y reglamentaria anexa, entonces, la regla fundamental en materia de reparación del daño la encontraremos en numeral tercero del artículo 1553 del Código Civil, que prevé:

"Si la obligación es de hacer y el deudor se constituye en mora, podrá pedir el acreedor, junto con la indemnización de la mora, cualquiera de estas tres cosas, a elección suya:

$1^{a}$. Que se apremie al deudor para la ejecución del hecho convenido;

$2^{a}$. Que se le autorice a él mismo para hacerlo ejecutar por un tercero a expensas del deudor; contrato."

$3^{a}$. Que el deudor le indemnice de los perjuicios resultantes de la infracción del

Y luego, de conformidad al artículo 1556 del Código Civil, dicha indemnización de perjuicios comprenderá, además del daño moral, el lucro cesante y daño emergente que se hubiere causado.

De conformidad con aquello, el trabajador que ha sufrido un accidente que estima ha sido causado por el incumplimiento del empleador, quien no ha aplicado en forma oportuna y/o suficiente aquellas medidas de seguridad a las que se encontraba obligado, puede perseguir su responsabilidad para que repare los daños que aquello le ha causado, debiendo acreditar los fundamentos de la responsabilidad que reclama, esto es: la existencia de una obligación contractual; que el deudor no haya realizado la conducta convenida en el contrato; 
que la inejecución de esa conducta sea susceptible de un reproche subjetivo u objetivo; que el incumplimiento haya causado daño al acreedor; y la existencia de relación de causalidad entre la inejecución de la conducta y el daño (Rodríguez, 2003: 27).

Es a partir de este punto que las características propias del contrato de trabajo comienzan a dificultar la aplicación pura y simple de las normas civiles sobre responsabilidad contractual, ya que, a diferencia de la generalidad de los contratos sinalagmáticos, el contrato de trabajo, dada la diferencia o desequilibrio existente entre las partes, está compuesto de una serie de reglas y mínimos de orden público, indisponibles para las partes, a través de los cuales el legislador suple la voluntad de las partes, estableciendo obligaciones que, pese a su origen legal, pasan a formar parte integrante del contrato. Como se advierte en las alegaciones que efectúan las partes en este tipo de procesos y en las sentencias que sobre ellos recaen, la circunstancia de verse el contrato de trabajo integrado por normas legales que establecen cargas dispares a las partes, se traduce en una serie de dificultades, principalmente, en relación con el tipo de culpa de la cual responderá el empleador y las cargas probatorias que gravan a cada parte del proceso, en efecto, la existencia de obligaciones tanto legales como contractuales, lleva a que muchas veces se invoquen indistintamente las normas que regulan tanto la responsabilidad contractual como la extracontractual.

A continuación, nos referiremos al modo en que se configura cada uno de los elementos que, de acuerdo a la doctrina antes citada, permiten establecer la existencia de responsabilidad civil contractual, en las acciones destinadas a perseguir tal responsabilidad en materia de accidentes del trabajo y las dificultades que cada uno presenta.

Como primer elemento, señalamos la existencia de una obligación contractual, este punto no reviste mayor dificultad cuando es el trabajador quien acciona en contra su empleador en sede laboral, bastando con acreditar la existencia de tal vínculo, dado que todo contrato de trabajo involucra, como parte de su contenido mínimo, el cumplimiento del llamado deber de seguridad (Gajardo, 2014: 24), (Gajardo, 2015: 32), que corresponde a la obligación del empleador de proteger la vida y seguridad de aquel trabajador que se pone bajo su subordinación y dependencia, obligación cuya base se encuentra prevista en el artículo 184 del Código del Trabajo, sin perjuicio de ser desarrollada y complementada en los artículos siguientes del mismo cuerpo legal, así como en otras normas legales y reglamentarias, tanto en lo referido a la prevención de accidentes y enfermedades profesionales, como en cuanto a la protección que debe darse una vez que tales riesgos se concretan.

En aquellos casos en que ya han operado las instituciones previstas en la Ley $\mathrm{N}^{\circ}$ 16.744 y el accidente o la enfermedad han sido previamente calificados de laborales a tales efectos, la existencia de este tipo de vínculo contractual entre las partes, con todas las obligaciones que trae aparejada, será un dato dado, que constará en los antecedentes emitidos por el organismo asegurador. Sin embargo, cuando la relación laboral no haya sido formalizada a través de un documento escrito, siendo negada por quien es emplazado en tanto empleador y, en consecuencia, cuando no haya operado el seguro de accidentes del trabajo y enfermedades profesionales, ello supondrá al tribunal una doble dificultad, ya que, en primer término, deberá determinar la existencia de la relación laboral, de la cual derivará su competencia para conocer del proceso, y sólo una vez superado ese requisito previo, pero, en el mismo proceso, deberá determinar si el accidente, que no fue atendido en su oportunidad por los organismos administradores de las prestaciones de salud profesional y que no ha recibido dicha calificación, corresponde de todos modos a un accidente del trabajo, por darse a su respecto los elementos descritos por el artículo $5^{\circ}$ de la Ley $\mathrm{N}^{\circ} 16.744$. La prueba de todas estas circunstancias será de carga del demandante, según se desprende de las reglas generales del onus probandi, consagradas en el artículo 1698 del Código Civil, las cuales no han sido modificadas en este punto por el Código del Trabajo, sin perjuicio, por cierto, de la 
procedencia de aplicar a las cuestiones debatidas, como podrá ocurrir con la determinación de la existencia del vínculo laboral, los principios propios del procedimiento laboral, tales como la primacía de la realidad.

El segundo elemento que deberá ser analizado por el Tribunal, es que el deudor no haya realizado la conducta convenida en el contrato y, dado que en materia de contrato de trabajo el empleador está obligado a cumplir con las obligaciones derivadas del deber de seguridad, normalmente este tipo de acciones se sustentarán en el incumplimiento de parte del empleador de aquella obligación general contenida en el artículo 184 del Código del Trabajo, sin perjuicio de la posibilidad de invocar otros incumplimientos referidos a aquellas normas legales y reglamentarias que lo complementan.

La mayor parte de las dificultades que plantea este elemento de la responsabilidad, vienen dadas precisamente por la redacción del citado artículo 184 del Código del Trabajo ${ }^{3}$, que construye una obligación de cuyo incumplimiento derivan importantes consecuencias a partir de conceptos jurídicamente indeterminados, tales como, la expresión "eficazmente", lo que ha llevado a plantear una serie de cuestionamientos en relación a la naturaleza de la obligación y las cargas probatorias. Así por ejemplo, se ha discutido si se trata de una obligación de medios o de resultados (Gajardo, 2014: 27) (Diez, 2005: 76-78), cuestión fundamental para establecer cuando nos encontraremos frente a un incumplimiento al mandato que aquella contiene; por otra parte, su uso, como si se tratase de una obligación de resultados, puede llevar a una cierta objetivación de la responsabilidad (Romero, 2005: 203), al permitir argumentar que cada vez que se produce un accidente, el empleador ha fallado en su obligación de proteger "eficazmente" la vida del trabajador, de modo que la propia ocurrencia del accidente serviría para acreditar el incumplimiento que haría al empleador responsable de indemnizar los perjuicios causados; asimismo, se ha discutido si en este tipo de procesos es el actor quien debe acreditar el incumplimiento de quien pretende responsable o es aquel quien debe probar el cumplimiento de su obligación contractual y legal, lo que podría traducirse en una alteración ilegítima de las cargas probatorias. Resulta evidente que la posición que adopten las partes y, en particular, el Tribunal respecto de estas cuestiones, será relevante cuando se trate de establecer si ha mediado o no un incumplimiento a tales normas integrantes del contrato de trabajo.

Por lo pronto, en lo que respecta a este segundo elemento, sostendremos que se trata de una obligación de medios, imponiendo al empleador la carga de adoptar, no solo algunas medidas de seguridad o aquellas a las cuales esté mínimamente obligado por las normas legales y reglamentarias que regulen la relación laboral y la propia actividad comercial o industrial que desarrolla el empleador, sino todas aquellas que aparezcan como necesarias, idóneas y posibles para lograr el fin buscado, cual es, proteger de manera lo más completa posible la vida y salud de los trabajadores a su cargo, entendemos que al emplearse la expresión "eficazmente", se ha pretendido que el empleador asuma un rol activo en la protección de los trabajadores, excediendo del mero cumplimiento formal de la norma, debiendo mantener una actitud constante de búsqueda e implementación de todos los medios disponibles para lograr el propósito previsto por la norma.

Malamente podría tratarse de una obligación de resultados, cuando la propia norma que establece obligaciones al empleador en materia de prevención de accidentes, también se pone en el caso de que estos puedan ser ocasionados por la concurrencia de una fuerza mayor o por el actuar culpable o doloso del trabajador o de terceros. Así lo hace, por ejemplo, el

\footnotetext{
${ }^{3}$ La norma señala que: "El empleador estará obligado a tomar todas las medidas necesarias para proteger eficazmente la vida y salud de los trabajadores, informando de los posibles riesgos y manteniendo las condiciones adecuadas de higiene y seguridad en las faenas, como también los implementos necesarios para prevenir accidentes y enfermedades profesionales."
} 
artículo $160 \mathrm{~N}^{\circ} 5$ del Código del Trabajo, que permite al empleador poner término a la relación laboral, cuando alguno de sus trabajadores cometa actos u omisiones que importen una imprudencia temeraria capaz de afectar la seguridad del establecimiento o salud de los trabajadores; en el mismo sentido, el artículo $5^{\circ}$ de la Ley $\mathrm{N}^{\circ} 16.744$, exceptúa del concepto de accidente del trabajo a aquellos debidos a fuerza mayor extraña que no tenga relación alguna con el trabajo y a aquellos producidos intencionalmente por la víctima; en tanto que el artículo 70 de la misma ley, establece que si el accidente se debió a negligencia inexcusable del trabajador, se le deberá aplicar una multa. De las normas anteriores es posible desprender con toda claridad, que la propia ley reconoce la posibilidad y se pone en el caso de que el accidente pueda ser causado debido a situaciones que escapan del ámbito de control del empleador, a quien, en consecuencia, se le asigna la carga de intentar evitar que tales situaciones se concreten, pero, en caso alguno es posible asumir que la sola ocurrencia del accidente supone un incumplimiento del empleador a sus obligaciones, ya que aun cumpliendo este con todas las obligaciones pertinentes, el accidente podría concretarse debido a alguna de estas situaciones ajenas al control del empleador.

Lo anterior, además, ratifica la existencia de un deber de autocuidado que pesa sobre el propio trabajador, quien, en su calidad de persona capaz, sujeto de derecho tanto dentro como fuera de la empresa, debe tener un rol preponderante en su propia protección. Por cierto, que al no poseer la facultad de dirección dentro de la empresa, el trabajador no puede dar órdenes u organizar los medios de producción y sistemas de trabajo con miras a evitar la ocurrencia de accidentes, pero, sí tiene la obligación de cumplir con las instrucciones dadas por su empleador en materia de seguridad y de advertir o poner en conocimiento de aquel cuando las medidas adoptadas no son suficientes o adecuadas para suprimir los riesgos o cuando se ha producido alguna situación debido, por ejemplo, a la intervención de terceros o de los elementos de la naturaleza, que pueda suponer un riesgo para él o para otros trabajadores. Sostener que el trabajador no tiene obligación alguna en el cuidado de su propia seguridad y que aquella solo descansa sobre el empleador, supone privarlo de aquella dignidad personal que las normas laborales con tanta fuerza le han reconocido, precisamente por ello, es que sostenemos que la situación cambia cuando el trabajador decide contratar a menores de edad, de conformidad al artículo 13 inciso segundo del Código del Trabajo, ya que, no obstante que la ley señale que obtenidas las autorizaciones pertinentes debe considerársele como plenamente capaz, lo cierto es que las reglas de la lógica y la experiencia nos deben llevar a concluir que no es posible exigirle a este trabajador menor de edad, la misma prudencia y cuidados en sus actos que resultan exigibles a un trabajador adulto, prudencia y cuidado que, en consecuencia, deben ser suplidos por un aumento de aquellos desplegados por el empleador.

El tercer elemento para determinar la existencia de responsabilidad contractual derivada del accidente, será que la inejecución de esa conducta sea susceptible de un reproche subjetivo u objetivo, vale decir, que el incumplimiento pueda ser imputado o atribuido a la parte, lo que requiere que esta haya estado en posición de poder cumplir la conducta y que, no obstante, no lo haya hecho, cuestión que nos lleva al problema de determinar cuál es el grado o tipo de culpa exigible al empleador en materia de seguridad.

Para ello debemos recordar que el artículo 44 del Código Civil, distingue tres tipos de culpa o descuido, cuales son:

"Culpa grave, negligencia grave, culpa lata, es la que consiste en no manejar los negocios ajenos con aquel cuidado que aun las personas negligentes y de poca prudencia suelen emplear en sus negocios propios. Esta culpa en materias civiles equivale al dolo.

Culpa leve, descuido leve, descuido ligero, es la falta de aquella diligencia y cuidado que los hombres emplean ordinariamente en sus negocios propios. Culpa o descuido, sin otra 
calificación, significa culpa o descuido leve. Esta especie de culpa se opone a la diligencia o cuidado ordinario o mediano. El que debe administrar un negocio como un buen padre de familia es responsable de esta especie de culpa.

Culpa o descuido levísimo es la falta de aquella esmerada diligencia que un hombre juicioso emplea en la administración de sus negocios importantes. Esta especie de culpa se opone a la suma diligencia o cuidado".

Ahora bien, supuesto que las partes de la relación laboral se encuentran unidas por un contrato que reporta beneficios recíprocos a las partes, y no sólo a una de ellas, de conformidad al artículo 1547 del mismo cuerpo legal, en principio, debiéramos considerar que el empleador es responsable de culpa leve, sin embargo, ello no es así. Como señaláramos previamente, dada la especial relación existente entre las partes que celebran un contrato de trabajo y atendido que el trabajador pone toda su persona a disposición del empleador, el legislador ha suplido la voluntad de las partes en una serie de aspectos del contrato, estableciendo obligaciones indisponibles para las partes, el deber de seguridad corresponde a ese tipo de obligaciones, deber que consagra una obligación que, según analizáramos previamente, va mucho más allá del cuidado que los hombres emplean ordinariamente en sus negocios propios. Al imponer la ley que el empleador debe proteger eficazmente la vida de los trabajadores, no está haciendo otra cosa, sino incrementar el nivel de diligencia exigido, que ya no será aquel que en virtud de todo contrato se adeudan las partes, sino uno superior, que a estos efectos podemos asimilar a la culpa levísima ${ }^{4}$, por cuanto el empleador está obligado a adoptar un sumo cuidado respecto de sus trabajadores, disponiendo todas las medidas que estén a su alcance para evitar la ocurrencia de los accidentes.

Dicho aquello, es necesario referirnos brevemente al problema de la prueba y si es correcto decir que en esta materia se "invierte" la carga de la prueba, cuando se le exige al empleador acreditar el haber obrado con aquella diligencia que la ley le exige en el marco del contrato de trabajo, pregunta que debe ser contestada en forma negativa. Lo anterior, por cuanto, el artículo 1698 del Código Civil, señala que "incumbe probar las obligaciones o su extinción al que alega aquéllas o ésta", lo que, en materia de responsabilidad derivada de accidentes del trabajo, supone que el trabajador demandante deberá acreditar la existencia de la relación laboral entre las partes, de la cual deriva la obligación del empleador en orden a velar por su seguridad, así como también deberá acreditar las circunstancias precisas en que se produjo el accidente, pero, hecho aquello y establecido, en consecuencia, que el accidente se produjo al interior de las faenas, cuando el trabajador realizaba determinada labor, será el empleador quien deberá acreditar que le proporcionó un ambiente de trabajo seguro para desarrollar tales labores, informándole de los riesgos y procedimientos de trabajo seguro, capacitándolo, entregándole los elementos de protección adecuados, entre las demás obligaciones que dispone la ley. Entregar dicha carga probatoria al empleador, no altera regla legal alguna, sino que corresponde al puro y simple cumplimiento de lo mandatado por el antes citado artículo 1547 inciso tercero del Código Civil, que señala: "La prueba de la diligencia o cuidado incumbe al que ha debido emplearlo; la prueba del caso fortuito al que lo alega". De suerte que, si el empleador sostiene que no es responsable del accidente por no existir un incumplimiento de su parte a sus obligaciones contractuales, o que éste se ha debido al caso fortuito o al incumplimiento del propio trabajador o de un tercero, es su parte quien debe acreditar tales hechos en los que funda sus defensas, de conformidad al antes citado artículo 1698 del Código Civil.

Luego, supuesto que se ha establecido la existencia de una obligación contractual, la inejecución de la conducta debida, la circunstancia de ser aquello reprochable al infractor,

\footnotetext{
${ }^{4}$ Este es el criterio adoptado, por ejemplo, en el considerando séptimo, de la sentencia dictada por la Excma. Corte Suprema, Hugo Alberto Aedo Gallardo con Nazar Logística Limitada (2014).
} 
debe, además, existir un daño susceptible de ser reparado, ya que sin daño no podría haber indemnización, dado que nuestro sistema de responsabilidad, tanto contractual como extracontractual, según se desprende de los artículos $1553 \mathrm{~N}^{\circ} 3$ y siguientes, y 2314 y siguientes, respectivamente, se basa en la reparación de los daños efectivamente causados, excluyendo la posibilidad de que, aun de no haberse causado daño, se ordenase el pago de una indemnización a título de sanción. Además, si bien la regla general es que el daño a reparar comprenda tanto el lucro cesante como el daño emergente, según dispone en materia de responsabilidad contractual el artículo 1556 del Código Civil, en materia de accidentes del trabajo y enfermedades profesionales, el artículo 69 b) de la ley 16.744, agrega el daño moral. En cualquier caso, la posibilidad de poder accionar también a fin de obtener la reparación de este daño, no excluye la obligación del trabajador de justificar el modo en que se ha producido cada daño y acreditar su existencia y monto, debiendo considerarse para su determinación, entre otros elementos, aquellas prestaciones que ya haya recibido por aplicación de la Ley $\mathrm{N}^{\circ}$ 16.744, punto sobre el cual volveremos más adelante.

Finalmente, para poder acceder a la indemnización pretendida, el trabajador debe acreditar la existencia de relación de causalidad entre la inejecución de la conducta y el daño, lo que dice relación con las circunstancias precisas en que ocurrió el accidente y sus causas. En efecto, para establecer la existencia de responsabilidad civil del empleador derivada del accidente del trabajo, no basta simplemente con que el trabajador sostenga que el empleador ha incumplido el deber general de seguridad, sino que debe explicar cómo lo ha infringido en concreto y cómo es que aquella infracción se relaciona de manera directa con el accidente, debiendo tratarse de un incumplimiento idóneo para causar la consecuencia que se pretende, de manera que suprimido mentalmente dicho incumplimiento desapareciese también el accidente. Así, por ejemplo, resultaría inocuo que un trabajador que se desempeña en una cocina y ha sufrido una quemadura con agua caliente, atribuyera el accidente a su empleador por no haberle entregado éste elementos de seguridad tales como casco o cuerdas de vida.

En cuanto a la relación causal, las defensas en este tipo de procedimientos suelen sostener que el accidente no se ha debido al incumplimiento del empleador, sino a uno del trabajador o a un caso fortuito, invocando en subsidio lo dispuesto en el artículo 2330 del Código Civil ${ }^{5}$, norma que se encuentra dentro de las disposiciones previstas en relación a la responsabilidad extracontractual y que, pese a ello, es comúnmente alegada por las defensas y aplicada en las sentencias que se dictan sobre la matera en sede laboral, donde lo discutido es la responsabilidad contractual del empleador. Tratándose de responsabilidad contractual, debiéramos sostener que, así como la culpa del trabajador o el caso fortuito podrían excluir la culpa del empleador, también es posible que nos encontremos frente a una hipótesis de concausas, en que se pueda sostener que la ocurrencia del accidente se ha debido tanto a la culpa o negligencia del empleador como a la del propio trabajador, en tal escenario, lo que correspondería es entender que la culpa susceptible de ser imputada o atribuida a cada parte se ve atenuada por aquella en que incurre su contraria, lo que debe ser considerado al momento de determinar el monto de la indemnización, proceso que igualmente nos lleva a una solución bastante similar a aquella a la cual nos conduce la aplicación de la norma antes indicada (ver Bahamondes y Pizarro, 2012: 39-52).

Establecidos los elementos anteriores, supuestos entre ellos que el trabajador ha acreditado la existencia de los daños en que funda sus pretensiones, debiéramos poder concluir que tiene derecho a percibir una indemnización que repare aquellos daños que ha acreditado, los que pueden comprender el lucro cesante, daño emergente y daño moral. En este punto, parece conveniente detenerse a fin de efectuar algunas precisiones respecto de la

\footnotetext{
${ }^{5}$ Norma que señala: "La apreciación del daño está sujeta a reducción, si el que lo ha sufrido se expuso a él imprudentemente".
} 
procedencia y cuantía de cada uno, en relación a la circunstancia de haber percibido o no, el trabajador, prestaciones emanadas de la seguridad social, sea de aquella obligatoria o complementaria, en forma previa.

Respecto del daño emergente, si lo definimos como el detrimento patrimonial efectivo que experimenta uno de los contratantes con ocasión del incumplimiento (Rodríguez, 2003: 226), debemos considerar que, en materia de accidentes del trabajo, cuando han operado los institutos previstos en la Ley $\mathrm{N}^{\circ} 16.744$, es muy difícil que este se produzca, ya que como hemos adelantado, el trabajador que accede a dichas prestaciones verá cubiertas las atenciones médicas que requiera, así como los medicamentos y traslados que ello suponga, percibiendo también un subsidio que reemplazará a la remuneración que no podrá producir como consecuencia de la incapacidad. Es por ello que una revisión de las causas en que se discuten este tipo de indemnizaciones, permite sostener que este tipo de daño es el menos demandado y que se encuentra entre los menos otorgados por los Tribunales, precisamente, en atención a que tales prestaciones ya han sido cubiertas por el sistema de seguridad social. En tanto que, en aquellos casos en que se logre establecer que el empleador ha impedido que el trabajador pueda acceder a las prestaciones que la ley le garantiza, para el caso de sufrir un accidente del trabajo o enfermedad profesional, resulta del todo ajustado a las normas antes analizadas y a la finalidad de las indemnizaciones en cuestión, que la reparación comprenda también aquellas atenciones médicas y gastos asociados a ellas que el trabajador haya debido solventar directamente, como consecuencia de acciones u omisiones culpables de su empleador, además de las remuneraciones que ha dejado de percibir como consecuencia de la incapacidad, cuya existencia y monto, deberán ser debidamente acreditadas en el proceso.

Respecto del lucro cesante sostendremos una posición idéntica a la anterior, en cuanto a que las indemnizaciones que se otorgaren respecto de este daño, deben tener en consideración aquellas prestaciones ya otorgadas, en su caso, por los sistemas de seguridad social a fin de evitar la doble reparación del mismo daño. Este daño, tradicionalmente definido como aquella ganancia, utilidad o beneficio económico que el contratante deja de obtener como consecuencia del incumplimiento (Rodríguez, 2003: 227), normalmente se vincula con las remuneraciones que el trabajador no podrá obtener en el futuro por haber visto mermada su capacidad de trabajo a consecuencia del accidente.

Lo anterior, supone que el trabajador deberá acreditar la existencia de aquella merma en la capacidad de trabajo en que funda su acción y, dado que nuestro sistema de protección frente a accidentes del trabajo distingue entre incapacidad temporal e invalidez, presumiblemente permanente, es que para poder sostener con un mínimo de certeza, necesaria para fundar cualquier decisión judicial, que su capacidad de trabajo se verá disminuida en el futuro, parece necesario que el trabajador cuente con una declaración de invalidez emitida por los organismos pertinentes de conformidad a la Ley $\mathrm{N}^{\circ} 16.744 \mathrm{o}$, al menos, una emitida por los organismos de salud común (no profesional), si es que su empleador le impidió acceder al régimen de salud profesional; por otra parte, dado que la existencia de una declaración de incapacidad o invalidez no importa el término del contrato de trabajo ${ }^{6}$, el trabajador que pretende el pago de esta indemnización deberá acreditar el término del contrato celebrado con aquel empleador a quien imputa responsabilidad en su accidente o su actual situación de cesantía, ya que si dicha relación laboral sigue vigente y el trabajador está aún en tratamiento, otorgada que sea el alta médica el empleador tiene la obligación de recibirlo nuevamente en la empresa y otorgarle las funciones convenidas en su contrato o aquellas que el trabajador

\footnotetext{
${ }^{6}$ Por el contrario, el artículo 161 bis del Código del Trabajo, declara que: “La invalidez, total o parcial, no es justa causa para el término del contrato de trabajo. El trabajador que fuere separado de sus funciones por tal motivo, tendrá derecho a la indemnización establecida en los incisos primero o segundo del artículo 163, según correspondiere, con el incremento señalado en la letra b) del artículo 168 ".
} 
pueda ejecutar con su capacidad remanente, sin causar detrimento en sus remuneraciones, situación que obstaría a que se pudiere establecer la existencia del lucro cesante, ya que el solo hecho de retomar el trabajador sus labores habituales desvirtuaría los fundamentos de este tipo de indemnizaciones; lo mismo que ocurrirá si, con posterioridad al accidente, el trabajador ha contratado con otro empleador en labores o condiciones similares a las que poseía al momento de ocurrir el accidente.

De contrario, si el trabajador cuenta con una declaración de invalidez total o parcial, y acredita que no sigue prestando los mismos servicios que ejecutaba al momento de sufrir el accidente y que no podrá contratarse en servicios similares, precisamente, a consecuencia de la disminución en su capacidad de trabajo, entonces podrá tener derecho a una indemnización por lucro cesante, cuyo monto debiera considerar la entidad del daño, representada por la porción de su capacidad de trabajo perdida a consecuencia del accidente y las posibilidades de actualizar dicha capacidad de trabajo mediante la adquisición de otra actividad u oficio que requiera de otras fuerzas o habilidades no afectadas, o afectadas en menor medida por el accidente. Pero, además, el Tribunal deberá considerar si el trabajador ya percibe una pensión de invalidez otorgada por las instituciones de seguridad social, puesto que, en tal caso, dado que ambas prestaciones apuntarían al mismo fin, cual es, reemplazar las remuneraciones que el trabajador no percibirá en el futuro como consecuencia del accidente, debe velar porque el mismo daño no sea reparado dos veces, ya que tal exceso supondría no una reparación sino un enriquecimiento sin causa de parte del trabajador, por ello sostenemos que en caso que se acredite la existencia de una invalidez causada por el accidente, si el trabajador tiene derecho al pago de una pensión de aquellas pagadas por el seguro obligatorio de accidentes del trabajo y enfermedades profesionales, tales montos deben ser rebajados de los que proceda otorgar como indemnización por lucro cesante, la que incluso podría llegar a $\$ 0$, si el daño resulta suficientemente reparado con las pensiones a que tenga derecho el trabajador.

Finalmente, el daño moral, entendido como todo daño causado a la persona en sí misma, física y psíquica, como todo atentado contra sus intereses extrapatrimoniales (Domínguez, 2000: 83), suele asociarse con el sufrimiento causado por el accidente, los daños funcionales y estéticos que ocasiona a la víctima, el modo en que afecta su vida social, relaciones familiares y sociales y, en definitiva, los cambios operados en su vida diaria respecto del modo en que la llevaba antes del accidente.

Dicho daño, lo mismo que los restantes elementos que configuran la responsabilidad, debe ser probado por la parte demandante, quien también debe establecer las consecuencias que el accidente ha provocado en cada uno de los aspectos de la personalidad o vida del trabajador que se pretenden afectados, pero, también debe aportar elementos que permitan determinar su cuantía, la que, atendida la propia naturaleza del daño, tan directamente vinculado con la propia persona del demandante y sus características particulares, debe ser evaluada caso a caso, en función del daño preciso que se ha causado al trabajador afectado, alejándose de los fines de este tipo de reparaciones, cualquier fórmula que pretenda tarifar este daño en función de criterios objetivos tales como edad, remuneración percibida a la época del accidente o porcentaje de pérdida de capacidad de ganancia, elementos que, por lo demás, más bien parecen reconducirnos a la determinación del lucro cesante, ya que tales intentos de objetivar el monto de la prestación, prescindirían de un elemento fundamental para este tipo de daños, cual es, la intensidad del dolor provocado al actor, cuestión que debe ser verificada en forma particular respecto de cada trabajador afectado. Asimismo, cabe precisar que, cosa distinta de la ausencia o prescindencia de la prueba del daño, es que, en esta materia, como sucede con todas aquellas que son objeto de conocimiento y resolución por parte de los Tribunales del Trabajo, la prueba sea valorada conforme a las reglas de la sana crítica y que, en aplicación de aquella, el Tribunal pueda arribar a presunciones que permitan establecer y 
cuantificar el daño, a partir de la aplicación de principios de la lógica y la experiencia sobre aquellos antecedentes probatorios agregados por las partes.

\section{V.- CONCLUSIONES}

Hemos visto que nuestro sistema jurídico, expresamente autoriza la convivencia de dos sistemas reparatorios, uno fundado en las normas y principios de la seguridad social y otro fundado en las normas y principios del derecho común, de lo cual se derivan importantes beneficios para el trabajador, quien puede obtener lo mejor de cada sistema.

En efecto, el trabajador puede contar con el seguro de accidentes del trabajo y enfermedades profesionales, que opera de manera inmediata ocurrido el accidente, para atender a las necesidades más urgentes que este supone, como son el acceso a las atenciones médicas y la mantención de su ingreso; y, luego, si estima que tales prestaciones no han logrado reparar el daño efectivamente causado, puede, además, accionar en contra de quien suponga responsable de tal accidente, sea el empleador o un tercero, para que sea condenado al pago de una indemnización que repare los distintos daños causados por el accidente.

Lo anterior, sin que la obtención de indemnizaciones fundadas en la responsabilidad civil del empleador o terceros, le suponga tener que renunciar a las prestaciones del seguro, ni que el acceso a estas se entienda como una renuncia a las acciones civiles pertinentes, todo lo cual redunda en la celeridad e integridad en la reparación obtenida a través de la actuación conjunta y complementaria de ambos sistemas.

Por otra parte, la intervención de los organismos previstos en la Ley $\mathrm{N}^{\circ} 16.744$, le significará un alivio probatorio, cuando pretenda ejercer la acción tendiente a perseguir la responsabilidad civil derivada del accidente. Ello, por cuanto, establecido por tales organismos el carácter laboral del accidente, aquello no será discutido nuevamente en el juicio laboral, dándose valor a lo resuelto por tales organismos, en cuanto a la calificación del accidente, diagnóstico, existencia de incapacidad o invalidez, entre otras cuestiones, lo que supone que el proceso en que se pretenda el pago de indemnizaciones que reparen los daños causados por el accidente, se centrará especialmente en las causas del accidente, a fin de determinar si existe responsabilidad civil del demandado en dicho proceso, y en la prueba y avalúo de los daños causados.

Ello, sin perjuicio de la necesidad de recordar que ambos sistemas tienen distintos supuestos de aplicación, de modo que la existencia de un accidente del trabajo, que bien podrá justificar por si sola el otorgamiento de las prestaciones médicas y pecuniarias previstas en la Ley $\mathrm{N}^{\circ} 16.744$, no se traduce necesariamente en la existencia de una responsabilidad civil del empleador, ni en la obligación de aquel de indemnizar los perjuicios causados, lo que, como es la regla general en materia de responsabilidad civil, requerirá como elemento previo e indispensable, la prueba respecto de los factores que permitirán atribuir las consecuencias del daño al empleador. En este caso, la existencia de un incumplimiento culpable a sus obligaciones contractuales, el nexo de causalidad existente entre dicho incumplimiento y el daño, así como la existencia y cuantía del mismo.

Ahora bien, como se trata de reparaciones complementarias, que aun cuando pretendan lograr distintos fines, emanan de un mismo hecho causante y favorecen al mismo afectado, es necesario que cada vez que se regule una indemnización de tipo civil, se considere al momento de determinar su monto, aquellas prestaciones ya otorgadas al demandante como consecuencia de la aplicación de la Ley $\mathrm{N}^{\circ} 16.744$, o de otros seguros 
complementarios que puedan haber actuado, de modo de evitar con ello un reparación doble del mismo daño, que pueda traducirse en un enriquecimiento ilícito o sin causa de la víctima.

\section{BIBLIOGRAFLA}

BAHAMONDES O., Claudia y PIZARRO W., Carlos (2012), "La exposición de la víctima al daño: desde la culpabilidad a la causalidad", en: Revista de Derecho de la Pontificia Universidad Católica de Valparaíso [online]. 2012, n.39, disponible en: http://www.scielo.cl/scielo.php?script=sci_arttext\&pid=S071868512012000200001\&lng=es\&nrm=iso.

CIFUENTES LILLO, Hugo; ARELLANO ORTIZ, Pablo; WALKER ERRÁZURIZ, Francisco (2013). Seguridad social: Parte general y pensiones, Santiago, Editorial Librotecnia.

DIEZ SCHWERTER, José Luis (2005). "La culpa del empresario por accidentes del trabajo: modernas tendencias jurisprudenciales", en: La responsabilidad por accidentes del trabajo, Facultad de Derecho de la Universidad de Los Andes, Cuadernos de Extensión Jurídica $\mathrm{N}^{\circ} 10$.

DOMÍNGUEZ ÁVILA, Ramón (2011). "Los accidentes del trabajo. Historia y visión general de su régimen actual”, en: Responsabilidad civil del empresario por accidentes del trabajo $y$ enfermedades profesionales, Facultad de Derecho de la Universidad de Los Andes, Cuadernos de Extensión Jurídica $\mathrm{N}^{\circ} 20$.

DOMÍNGUEZ HIDALGO, Carmen (2000). El daño moral, Tomo I, Chile, Editorial Jurídica de Chile.

GAJARDO HARBOE, María Cristina (2014). "El deber de seguridad", en: Revista chilena de derecho del trabajo y la seguridad social, Facultad de Derecho de la Universidad de Chile, Vol. 5, $\mathrm{N}^{\circ} 9$.

GAJARDO HARBOE, María Cristina, (2015). Accidentes del trabajo y enfermedades profesionales, Chile, Editorial Thomson Reuters.

HUMERES NOGUER, Héctor (2005). Derecho del trabajo y de la seguridad social, Tomo III, Editorial Jurídica de Chile, decimoséptima edición.

LANATA FUENZALIDA, Gabriela, (2015). Manual de legislación previsional, Editorial Thomson Reuters, segunda edición.

NOVOA FUENZALIDA, Patricio (1977). Accidentes del trabajo y enfermedades profesionales, Editorial Jurídica de Chile, primera edición.

RODRÍGUEZ GREZ, Pablo (2003). Responsabilidad contractual, Editorial Jurídica de Chile.

ROMERO SEGUEL, Alejandro (2005). "La competencia judicial en los accidentes del trabajo y el derecho de los justiciables frente al cambio en la jurisprudencia", en: La responsabilidad por accidentes del trabajo, Facultad de Derecho de la Universidad de Los Andes, Cuadernos de Extensión Jurídica $\mathrm{N}^{\circ} 10$.

ZELAYA ETCHEGARAY, Pedro, (2005). "La responsabilidad subsidiaria del duelo de obra por los accidentes y daños experimentados por el trabajador del contratista", en: La responsabilidad por accidentes del trabajo, Facultad de Derecho de la Universidad de Los Andes, Cuadernos de Extensión Jurídica $\mathrm{N}^{\circ} 10$.

\section{JURISPRUDENCIA JUDICIAL CITADA}

"Castro con Superintendencia", (2009). Jugado de Letras del Trabajo de Concepción; de 18 de noviembre de 2009: RIT O-547-2009, 
"Carrasco con Superintendencia", (2011). Segundo Juzgado de Letras del Trabajo de Santiago; del 12 de octubre de 2011, RIT O-2724-2011.

"Correa con Superintendencia”, (2001). Segundo Juzgado de Letras del Trabajo de Santiago; O-1424-2001.

"Damianovic con Superintendencia", (2011). Segundo Juzgado del Trabajo de Santiago; de 26 de diciembre de 2011, O-3684-2011.

"Herrera con Superintendencia", (2011). Juzgado de Letras del Trabajo de Calama; de 16 de noviembre de 2011, Rit O-247-2011.

Hugo Alberto Aedo Gallardo con Nazar Logística Limitada. (2014). Excma. Corte Suprema, de 24 de noviembre de 2014, Rol 2547-2014, (Recurso de unificación de jurisprudencia, acogido). 